\title{
Maternal socioeconomic status and the risk of asthma among offspring
}

\author{
Maijakaisa Harju ${ }^{1,2^{*}}$, Leea Keski-Nisula ${ }^{1,2}$, Leena Georgiadis ${ }^{1}$, Kaisa Raatikainen ${ }^{1,2}$, Sari Räisänen ${ }^{1}$ \\ and Seppo Heinonen ${ }^{1,2,3}$
}

\begin{abstract}
Background: To evaluate the association between maternal socioeconomic status (SES) during pregnancy and asthma among offspring.

Methods: A retrospective observational hospital-based birth cohort study in a university-based Obstetrics and Gynecology department in Finland. A total of 40118 women with singleton live births between 1989 and 2007 were linked with data from the register for asthma medication for their offspring $(n=2518)$. Pregnancy and maternal SES factors were recorded during pregnancy and labor. SES was categorized thus: upper white-collar workers (highest SES), lower white-collar workers, blue-collar workers, others (lowest SES) and cases with missing information. Logistic regression analysis was used to determine the association between maternal SES and childhood asthma.

Results: We found no convincing evidence of a direct association between maternal SES and childhood asthma. Parental smoking was the clearest factor affecting asthma among children of lower white-collar workers. Differences in pregnancy and delivery characteristics were observed between the SES groups.
\end{abstract}

Conclusions: Maternal socioeconomic status had no significant direct impact on the prevalence of asthma in this Finnish birth cohort. Finnish public health services appeared to offer equal quality services independently of SES.

Trial registration: The study is registered in Kuopio University Hospital register (TUTKI): ID5302448.

Keywords: Asthma, SES, Childhood, Pregnancy

\section{Background}

Asthma and allergic diseases in childhood affect nearly $10 \%$ of children worldwide, the prevalence being lowest in Asian countries (2-4\%) and highest in developed countries $(15-20 \%)[1,2]$. The prevalence has been increasing in recent decades, although part of the increase might be due to increased rates of reporting and awareness of the symptoms [3]. Both pre- and postnatal factors play an important role in the development of asthma $[2,4,5]$. Early epigenetic programming of asthma and allergy is suggested to occur in utero, where various forms of prenatal exposure such as maternal smoking, stress and anxiety, infections, infertility treatment and

\footnotetext{
* Correspondence: maijakaisa.harju@kuh.fi

'Department of Obstetrics and Gynecology, Kuopio University Hospital, Kuopio, Finland

${ }^{2}$ University of Eastern Finland, Faculty of Health Sciences, Kuopio, Finland Full list of author information is available at the end of the article
}

restricted fetal growth might affect development of the fetal immune system [3-6]. Furthermore, potential risk factors related to delivery and the neonatal period include prematurity, low birth weight, birth mode and early-life infections $[1,3,4,7]$. In addition, parental history of asthma, male sex and exposure to certain environmental factors have been associated with asthma in childhood [2-4]. All of these perinatal factors are linked to parental socioeconomic status (SES) and thus socioeconomic disparities may influence the burden of asthma.

Finland has had a highly developed publicly funded primary healthcare system for many decades, every pregnant woman receiving free or low-cost high-quality maternity care during pregnancy and delivery. More than $98 \%$ of all deliveries occur in publicly owned birth hospitals. Recently, Räisänen and associates showed in a large birth register study in Finland that low maternal SES strongly determined the need of cesarean delivery [8], as 
well as being a strong predictor of small-for-gestationalage (SGA) infants [9]. The aim of the present study was to identify perinatal differences between socioeconomic groups and to clarify their contribution to asthma among offspring by conducting an observational study using hospital-based birth register data on 40118 women and their singleton live-born infants in 1989-2007 in Finland.

\section{Methods}

Data were collected from the Kuopio University Hospital clinical birth database, covering 42205 infants who were born after 23 completed weeks of gestation between 1989-2007. We excluded multiple pregnancies, stillbirths and neonatal deaths. After these exclusions, data on 40 118 women with singleton live-born infants were linked with data from the register for asthma medication for their offspring aged $1-19$ years $(\mathrm{n}=2518)$.

Information on maternal pre-pregnancy characteristics was based on data from self-administered questionnaires at 20 weeks of pregnancy. Midwives and public health nurses completed missing data by interviewing during visits to prenatal maternal clinics or labor wards at Kuopio University Hospital. The questionnaire covered 75 background items [10]. At the time of childbirth and during the neonatal period nurses and midwives added information on pregnancy, delivery, neonatal outcomes and complications to the database. Informed consent for this register study was given by childbearing women at the time of data collection.

Information on the need for anti-asthmatic drugs during childhood was obtained from the Drug Prescription Register of the Social Insurance Institution. Anti-asthmatic drugs were explored and categorized according to FIMEA (Finnish Medicines Agency) ATC((Anatomical Therapeutic Chemical)-groups: R03, R06, drugs for obstructive airway diseases consisting of as-needed inhaled beta2agonists, inhaled glucocorticoids, inhaled long acting beta2-agonists and antileukotrienes [11]. In Finland, all medication is prescribed by physicians, and in the case of pediatric asthma, usually by pediatricians, and reimbursed at a rate of $72 \%$ via the National Sickness Insurance Scheme [12]. The diagnosis of asthma among offspring was evaluated in two different ways in this study: based on the doctor diagnosed asthma (set by a paediatrician using ICD code) and based on the information on over six month continuous use of anti-asthmatic drugs. Permission for the use of register data in scientific research was granted by the register-keeping organization. Information on maternal socioeconomic status was based on the mother's occupation at the time of birth based on the EU's classification of occupations ISCO-88(COM) [13]. At first, five SES classes were categorized: upper white-collar workers such as teachers and physicians, lower white-collar workers such as nurses and secretaries, blue-collar workers such as cooks and cleaners, "other", which included housewives, students, and unemployed and retired people, as described in detail elsewhere [14], and entrepreneurs. Entrepreneurs were separated into a different group in our data and consisted mainly of producers of agricultural goods. Since they constituted only $2.9 \%$ of all study women, this group was included in "other", making classification similar to that in previous Finnish studies $[9,14]$. Information on SES was missing in $2324(5.8 \%)$ cases and this group was analyzed separately.

Statistical analyses were performed by using SPSS 21.0 for Windows. Pearson's chi-square and Mann-Whitney $U$ tests were used to analyze univariate data on maternal and prenatal pregnancy characteristics and SES.

Multivariate logistic regression analysis was performed to model the association between asthma among offspring, and maternal SES. Confounding risk factors were selected on the basis of univariate analysis using a cutoff $\mathrm{p}$ value of $<0.05$ for factors with known clinical importance. The multivariate analyses were adjusted for maternal asthma (no vs. yes), maternal hypertension (no vs. yes), maternal parity $(0, \geq 1)$, ART (assisted reproduction technology before the index pregnancy (no vs. yes)), parental smoking (nonsmoking parents, maternal or paternal smoking, both parents smokers), mode of delivery (vaginal vs. cesarean), child's sex and gestational weeks at birth $(<37,37-40, \geq 41$ weeks). Furthermore, the children's follow-up time was taken into account by using the child's age at the onset of asthma or age at the end of the study among healthy children (2007). Upper whitecollar workers were selected as the reference group, where the incidence of asthma was nearest to its mean prevalence. Differences were deemed to be significant if $\mathrm{p}$ was $<0.05$.

The study was approved by Ethics Research Committee of Kuopio University Hospital and the Committee gave permission for the results to be published (93//2008).

\section{Results}

The study population covered 40118 singleton live births, among which 2518 (6.3\%) offspring had asthma during childhood. The mean age was 4.2 years at the onset of asthma and $82.3 \%$ of these children were aged more than seven years at the time of the study. Compared with controls, asthmatic children were more frequently males born by cesarean delivery, at lower gestational age and more frequently with birth weight under 2500 grams and small for gestational age (SGA). In addition, they were born more often to mothers with asthma and hypertension and to parents who smoked during pregnancy. Furthermore, their mothers had received more infertility treatments before pregnancy compared with the controls. Prevalence of asthma was highest among 
Table 1 Basic maternal and perinatal characteristics of the study population in relation to asthma ever

\begin{tabular}{|c|c|c|c|}
\hline Characteristics & $\begin{array}{l}\text { No asthma } \\
\mathrm{N}(\%)\end{array}$ & $\begin{array}{l}\text { Asthma } \\
\mathrm{N}(\%)\end{array}$ & $p$ value \\
\hline \multicolumn{4}{|l|}{ Maternal age, years } \\
\hline$<20$ & $1246(3.3)$ & $69(2.7)$ & \\
\hline $20-29$ & $19613(52.3)$ & $1366(54.2)$ & \\
\hline $30-39$ & $15544(41.3)$ & 1015(40.3) & \\
\hline$\geq 40$ & 1197(3.2) & $68(2.7)$ & 0.083 \\
\hline Maternal parity, primiparous & $15359(40.7)$ & $967(38.4)$ & 0.016 \\
\hline Maternal asthma & $1016(2.7)$ & $113(4.5)$ & $<0.001$ \\
\hline $\begin{array}{l}\text { Maternal gestational diabetes } \\
\text { mellitus }\end{array}$ & $2619(7.0)$ & 143(5.7) & 0.014 \\
\hline Maternal hypertension & $716(1.9)$ & $74(2.9)$ & $<0.001$ \\
\hline $\begin{array}{l}\text { Assisted reproduction } \\
\text { technology, index pregnancy }{ }^{1}\end{array}$ & $1514(4.0)$ & $142(5.6)$ & $<0.001$ \\
\hline \multicolumn{4}{|l|}{ Pre-pregnancy $\mathrm{BMI}^{*}, \mathrm{~kg} / \mathrm{m}^{2}$} \\
\hline$<25$ & $25675(71.4)$ & 1702(70.6) & \\
\hline $25-29.9$ & 7105(19.8) & 480(19.9) & \\
\hline$\geq 30$ & $3182(8.8)$ & $228(9.5)$ & 0.557 \\
\hline \multicolumn{4}{|l|}{ Marital status } \\
\hline Unmarried & $3938(10.5)$ & 274(10.9) & \\
\hline Married or cohabiting & $33662(89.5)$ & $2244(89.1)$ & 0.518 \\
\hline \multicolumn{4}{|l|}{ Socioeconomic status } \\
\hline Upper white-collar worker & $5375(14.3)$ & $359(14.3)$ & \\
\hline Lower white-collar worker & $13790(36.7)$ & $973(38.6)$ & \\
\hline Blue-collar worker & $7528(20.0)$ & $477(18.9)$ & \\
\hline Entrepreneurs & 1115(3.0) & $52(2.1)$ & \\
\hline Other & $7582(20.2)$ & $543(21.6)$ & \\
\hline Missing & 2210(5.9) & $114(4.5)$ & 0.001 \\
\hline \multicolumn{4}{|l|}{ Parental smoking** } \\
\hline Non-smoking parents & $19215(55.2)$ & $1240(52.3)$ & \\
\hline Maternal/paternal smoking & 8992(25.8) & $633(26.7)$ & \\
\hline Both smoking parents & $6620(19.0)$ & $498(21.0)$ & 0.013 \\
\hline \multicolumn{4}{|l|}{ Mode of delivery } \\
\hline Vaginal & 31 288(83.2) & $2000(79.4)$ & \\
\hline Cesarean delivery & 6312(16.8) & $518(20.6)$ & $<0.001$ \\
\hline Sex of child, boy & $18940(50.4)$ & $1521(60.4)$ & $<0.001$ \\
\hline \multicolumn{4}{|l|}{ Gestational age at birth, weeks } \\
\hline$<28$ & $129(0.3)$ & $50(2.0)$ & \\
\hline $28-32$ & $341(0.9)$ & $80(3.2)$ & \\
\hline $33-36$ & 1579(4.2) & $149(5.9)$ & \\
\hline $37-40$ & $26253(69.8)$ & $1724(68.5)$ & \\
\hline$\geq 41$ & $9298(24.7)$ & $515(20.5)$ & $<0.001$ \\
\hline Birth weight $<2500$ grams & 1482(3.9) & $221(8.8)$ & $<0.001$ \\
\hline Small for gestational age (SGA) & $13569(9.5)$ & $263(10.4)$ & 0.117 \\
\hline
\end{tabular}

Table 1 Basic maternal and perinatal characteristics of the study population in relation to asthma ever (Continued)

Asthma prevalence by age group, years

$1-6$
$7-12$
$\geq 13$

Mean age at the onset of asthma, years $( \pm S D)$

Total study population

$\begin{array}{lll}13251(35.2) & 445(17.7) & \\ 10390(27.6) & 945(37.5) & \\ 13959(37.1) & 1128(44.8) & <0.001 \\ & 4.2(3.5) & \\ & & \\ 37600(93.7) & 2518(6.3)\end{array}$

${ }^{1}$ Assisted reproduction technology before index pregnancy including in vitro fertilization, intra-cytoplasmic sperm injection, insemination and ovulation induction by clomifene citrate and other medicines. ${ }^{2}$ BMI: kilograms/square meters.

*Body mass index, data missing 1746 (4.4\%) cases. **Data missing 2920 (7.3\%) cases.

lower white-collar workers and lowest among entrepreneurs (Table 1).

We further evaluated maternal and prenatal differences between the various socioeconomic groups (Tables 2 and 3 ). As expected, Table 2 shows that all but one of the evaluated maternal characteristics was significantly associated with socioeconomic factors. Upper white-collar workers were older, more often married, with lower BMI, with a high rate of fertility problems and with a low number of pregnancies and artificial abortions compared with the other SES groups. Over $60 \%$ of the blue-collar workers were less than 30 years of age, $10.6 \%$ were heavily overweight, in 26.45 of cases both parents smoked and they had more previous artificial abortions than the other groups.

Maternal socioeconomic factors were also associated very strongly with most of the studied prenatal factors (Table 3). Upper white-collar workers more often had fear of childbirth, but less preeclampsia and they smoked less during pregnancy. They delivered more often at term by elective cesarean delivery than their counterparts with lower SES. Their neonates had the highest birth weights, the lowest incidence of being SGA with low birth weight, but interestingly they most often needed neonatal intensive care unit treatment after birth. In contrast, preterm birth, preeclampsia, cesarean delivery during labor and birth after 41 weeks of gestation, with lower Apgar scores, were more common among blue-collar workers compared with the other SES groups.

In univariate analysis, children in the "other" group (including housewives, the unemployed and students) had the highest rate of asthma (6.4\%), but no clear differences were detected between groups (e.g. upper whitecollar vs. blue-collar workers; $6.3 \%$ vs. $6.0 \%$ ). In this analysis, the children of entrepreneurs had the lowest prevalence of asthma (4.5\%), but since entrepreneurs constituted only $2.9 \%$ of all study women, they were not analyzed separately but included in the "other" group. 
Table 2 Maternal background characteristics by socioeconomic status (SES)

\begin{tabular}{|c|c|c|c|c|c|c|c|}
\hline & Total n(\%) & $\begin{array}{l}\text { Upper white-collar } \\
\text { worker } \mathrm{n}(\%)\end{array}$ & $\begin{array}{l}\text { Lower white-collar } \\
\text { worker } \mathrm{n}(\%)\end{array}$ & $\begin{array}{l}\text { Blue-collar } \\
\text { worker } n(\%)\end{array}$ & Other $\mathrm{n}(\%)$ & Missing n(\%) & $p$ value \\
\hline \multicolumn{8}{|l|}{ Maternal age, years } \\
\hline$<20$ & 1315(3.3) & $10(0.2)$ & $125(0.8)$ & $196(2.4)$ & $788(8.5)$ & 196(8.4) & \\
\hline $20-29$ & $20979(52.3)$ & $2087(36.4)$ & $7426(50.3)$ & $4629(57.8)$ & $5658(60.9)$ & $1179(50.7)$ & \\
\hline $30-39$ & $16559(41.3)$ & $3406(59.4)$ & $6728(45.6)$ & 2942(36.8) & $2617(28.2)$ & $866(37.3)$ & \\
\hline$\geq 40$ & $1265(3.2)$ & $231(4.0)$ & $484(3.3)$ & $238(3.0)$ & $229(2.5)$ & $83(3.6)$ & $<0.001$ \\
\hline Asthma & $1129(2.8)$ & $136(2.4)$ & $438(3.0)$ & $172(2.1)$ & 285(3.1) & $98(4.2)$ & $<0.001$ \\
\hline Hypertension & $790(2.0)$ & $94(1.6)$ & $325(2.2)$ & $158(2.0)$ & $169(1.8)$ & $44(1.9)$ & 0.074 \\
\hline $\mathrm{ART}^{1}$ & $1656(4.1)$ & $327(5.7)$ & $717(4.9)$ & 304(3.8) & $244(2.6)$ & $64(2.8)$ & $<0.001$ \\
\hline Infertility (own opinion) & $2290(5.7)$ & $489(8.5)$ & $971(6.6)$ & $428(5.3)$ & $316(3.4)$ & $86(3.7)$ & $<0.001$ \\
\hline \multicolumn{8}{|l|}{ Pre-pregnancy $\mathrm{BMI}^{2}, \mathrm{~kg} / \mathrm{m}^{2}$} \\
\hline$<25$ & $27377(71.3)$ & $4232(76.7)$ & $10140(71.2)$ & $5180(67.4)$ & $6439(72.1)$ & $1386(69.2)$ & \\
\hline $25-29.9$ & $7585(19.8)$ & $975(17.7)$ & $2871(20.2)$ & $1690(22.0)$ & $1659(22.0)$ & $390(19.5)$ & \\
\hline$\geq 30$ & $3410(8.9)$ & $310(5.6)$ & $1227(8.6)$ & $815(10.6)$ & $831(9.3)$ & $227(11.3)$ & $<0.001$ \\
\hline \multicolumn{8}{|l|}{ Marital status } \\
\hline Unmarried & $4212(10.5)$ & $360(6.3)$ & 1364(9.2) & 1038(13.0) & 1110(11.9) & $340(14.6)$ & \\
\hline Married or cohabiting & $35906(89.5)$ & $5374(93.7)$ & 13 399(90.8) & $6967(87.0)$ & $8182(88.1)$ & 1984(85.4) & $<0.001$ \\
\hline Mean number of deliveries ${ }^{3}$ & $1.0(1.3)$ & $1.0(1.2)$ & $1.0(1.1)$ & $1.0(1.2)$ & $1.3(1.6)$ & $0.9(1.3)$ & $<0.001$ \\
\hline Mean number of pregnancies ${ }^{3}$ & $1.4(1.6)$ & $1.3(1.5)$ & $1.4(1.4)$ & $1.4(1.5)$ & $1.7(2.0)$ & $1.4(1.6)$ & $<0.001$ \\
\hline Mean numbers of miscarriages ${ }^{3}$ & $0.2(0.6)$ & $0.2(0.6)$ & $0.2(0.5)$ & $0.2(0.5)$ & $0.2(0.6)$ & $0.2(0.6)$ & 0.004 \\
\hline Mean number of artificial abortions ${ }^{3}$ & $0.1(0.4)$ & $0.1(0.3)$ & $0.1(0.4)$ & $0.2(0.5)$ & $0.1(0.4)$ & $0.2(0.4)$ & 0.001 \\
\hline Surgically scarred urerus & $3590(8.9)$ & 513(8.9) & 1325(9.0) & 776(9.7) & $831(8.9)$ & $145(6.2)$ & $<0.001$ \\
\hline Total & $40118(100)$ & $5734(14.3)$ & $14763(36.8)$ & $8005(20.0)$ & $9292(23.2)$ & $2324(5.8)$ & \\
\hline
\end{tabular}

${ }^{1}$ Assisted reproduction technology before index pregnancy including in vitro fertilization, intracytoplasmic sperm injection, insemination and ovulation induction by clomifene and other medizines.

${ }^{2}$ Body mass index, data missing in 1746 (4.4\%) cases.

${ }^{3}$ Data are presented as mean $( \pm S D)$.

In adjusted analysis, no significant differences were detected in the risk of asthma among offspring in relation to maternal SES at the time of pregnancy (Table 4). Belonging to the "missing" group (maternal SES not defined) was associated with a protective effect against asthma (aOR 0.42, 95\% CI 0.32-0.54), reflecting the fact that the group was very heterogeneous.

\section{Discussion}

The overall prevalence of asthma among children was $6.3 \%$, varying between $4.9-6.6 \%$ in the different maternal socioeconomic groups. We detected no significant associations in univariate or in multivariate analysis between maternal SES and asthma after defining four SES groups (upper-white collar workers, lower white-collar workers, blue-collar workers, and "other"). Our results are in line with those of previously published studies and support the concept that the etiology of asthma is multifactorial [15]. However, in subgroup analysis the children of entrepreneurs had the lowest prevalence of asthma (4.5\%). Since this professional group represented only $2.9 \%$ of the pregnant women, the group was underpowered to be analyzed individually in multivariate analysis, but it was included in the "other" group. In our area, interestingly, female entrepreneurs were most commonly farmers, and according to earlier reports, a low prevalence of asthma among farmers' children is an expected finding.

We found that mothers with lower SES (blue-collar and others) were often multiparous women delivering vaginally $(82.8-85.3 \%)$ at term or after (93.9-94.4\%), factors known to be protective against asthma $[1,3,16]$. Ekblad et al. (2013) reported that smoking was more likely among teenagers in single-mother and lower-SES groups [17]. We found similar results, since up to a fourth of parents smoked during pregnancy in the lower-SES groups. They were also twice as often unmarried compared with those in the higher-SES groups (13\%; 6.3\%) and over $60 \%$ of mothers in the lower-SES groups were under 30 years of age and among the lowest ("other") group $8.5 \%$ were under 20 years of age. Prenatal protective factors, such as lower infertility, maternal multiparity and vaginal delivery might be reasons for the 
Table 3 Prenatal characteristics by maternal socioeconomic status (SES)

\begin{tabular}{|c|c|c|c|c|c|c|c|}
\hline & Total & $\begin{array}{l}\text { Upper white-collar } \\
\text { worker } n(\%)\end{array}$ & $\begin{array}{l}\text { Lower white-collar } \\
\text { worker } n(\%)\end{array}$ & $\begin{array}{l}\text { Blue-collar } \\
\text { worker } n(\%)\end{array}$ & Other $\mathrm{n}(\%)$ & Missing $n(\%)$ & $p$ value \\
\hline Primiparous & $16326(40.7)$ & $2346(40.9)$ & $6006(40.7)$ & $3221(40.2)$ & $3572(38.4)$ & $1181(50.8)$ & \\
\hline Multiparous & $23792(59.5)$ & $3388(59.1)$ & $8757(59.3)$ & 4784(59.8) & $5720(61.6)$ & 1143(49.2) & $<0.001$ \\
\hline Gestational diabetes mellitus & $2762(6.9)$ & $350(6.1)$ & 1086(7.4) & $565(7.1)$ & $540(5.8)$ & $221(9.5)$ & $<0.001$ \\
\hline Pre-eclampsia & 1466(3.7) & $175(3.1)$ & $593(4.0)$ & $325(4.1)$ & 297(3.2) & $76(3.3)$ & $<0.001$ \\
\hline Fear of childbirth* & $625(1.6)$ & $98(1.7)$ & $242(1.6)$ & $83(1.0)$ & 152(1.6) & $50(2.2)$ & $<0.001$ \\
\hline \multicolumn{8}{|l|}{ Parental smoking** } \\
\hline Non-smoking & $20455(55.0)$ & $3919(72.5)$ & $7946(57.3)$ & $3352(44.5)$ & $4382(51.0)$ & $856(47.6)$ & \\
\hline Maternal/paternal smoking & $9625(25.9)$ & 1060(19.6) & $3716(26.8)$ & 2193(29.1) & $2197(25.5)$ & $459(25.5)$ & \\
\hline Smoking & 7118(19.1) & $425(7.9)$ & 2195(15.8) & 1993(26.4) & $2020(23.5)$ & $485(26.9)$ & $<0.001$ \\
\hline \multicolumn{8}{|l|}{ Mode of delivery } \\
\hline Vaginal & $33280(83.0)$ & $4685(81.7)$ & $12138(82.2)$ & $6629(82.8)$ & $7929(85.3)$ & 1899(82.0) & \\
\hline Elective cesarean & $3176(7.9)$ & $527(9.2)$ & 1226(8.3) & $599(7.5)$ & $624(6.7)$ & $200(8.6)$ & \\
\hline Cesarean section during labour & $3654(9.1)$ & $522(9.1)$ & 1399(9.5) & $777(9.7)$ & $739(8.0)$ & $217(9.4)$ & $<0.001$ \\
\hline Sex of child, Boy & $20461(51.0)$ & 2940(51.3) & $7550(51.1)$ & 3995(49.9) & $4753(51.2)$ & 1223(52.6) & 0.155 \\
\hline \multicolumn{8}{|l|}{ Gestatonal age at birth, weeks } \\
\hline$<37$ & 2325(5.5) & $290(5.1)$ & $854(5.8)$ & $491(6.1)$ & $515(5.5)$ & $175(7.5)$ & \\
\hline $37-40$ & $27977(69.7)$ & 4103(71.6) & $10334(70.0)$ & $5456(68.2)$ & $6487(69.8)$ & $1597(68.7)$ & \\
\hline$\geq 41$ & $9813(24.5)$ & $1340(23.4)$ & $3575(24.2)$ & $2056(25.7)$ & $2290(24.6)$ & $552(23.8)$ & $<0.001$ \\
\hline Mean birth weight, grams*** & $3517(589)$ & $3541(560)$ & $3525(587)$ & $3496(602)$ & $3523(584)$ & $3457(642)$ & 0.001 \\
\hline Apgar score $<7$ at $5 \mathrm{~min}$ & $689(1.7)$ & $91(1.6)$ & $246(1.7)$ & 144(1.8) & 152(1.6) & $56(2.4)$ & 0.089 \\
\hline Care in Intensive Care Unit(NICU) & $3466(8.6)$ & $517(9.0)$ & 1298(8.8) & $701(8.8)$ & $729(7.8)$ & $221(9.5)$ & 0.024 \\
\hline Placental abruption & $257(0.6)$ & $38(0.7)$ & $74(0.5)$ & $71(0.9)$ & $54(0.6)$ & $20(0.9)$ & 0.006 \\
\hline Birth weight $<2500 \mathrm{~g}$ & $1703(4.2)$ & 193(3.4) & $606(4.1)$ & $375(4.7)$ & $381(4.1)$ & $148(6.4)$ & $<0.001$ \\
\hline Small for gestational age & 3832(9.6) & $500(8.7)$ & 1316(8.9) & $882(11.0)$ & $867(9.3)$ & 267(11.6) & $<0.001$ \\
\hline Total & $40118(100)$ & $5734(14.3)$ & $14763(36.8)$ & $8005(20.0)$ & $9292(23.2)$ & 2324 (5.8) & \\
\hline
\end{tabular}

*Data available years in 1996-2007.

**Data available in 37198 cases.

***Data are presented as mean (SD).

lower prevalence of asthma among lower-SES groups, since smoking, known to be a significant risk factor of asthma $[1,18]$, was more prevalent among these lowerSES groups compared with lower white-collar workers, where asthma was most common (6.6\%). Inclusion of entrepreneurs, consisting mostly of agricultural producers with a low risk of offspring asthma, diminished asthma prevalence as a net effect among children in the "other" group.

In our large register-based study, some obstetric disparities were found between the different socioeconomic groups. We showed that elective cesarean delivery

Table 4 Risk of asthma ever among offspring by maternal socioeconomic status (SES)

\begin{tabular}{|c|c|c|c|c|c|c|}
\hline SES & Total n(\%) & Asthma n(\%) & $\mathrm{OR}(95 \% \mathrm{Cl})$ & $p$ value & aOR(95\% Cl)* & $\mathrm{p}$ value \\
\hline Upper white-collar worker & $5734(14.3)$ & $359(6.3)$ & 1 & & 1 & \\
\hline Lower white-collar worker & $14763(36.8)$ & $973(6.6)$ & 1.06(0.93-1.20) & 0.390 & 1.02(0.89-1.16) & 0.816 \\
\hline Blue-collar worker & $8005(20.0)$ & $477(6.0)$ & 0.95(0.82-1.09) & 0.465 & $1.01(0.86-1.17)$ & 0.950 \\
\hline Other & $9292(23.2)$ & $595(6.4)$ & 1.02(0.90-1.17) & 0.728 & 1.02(0.88-1.18) & 0.776 \\
\hline Missing & 2324(5.8) & 114(4.9) & $0.77(0.62-0.96)$ & 0.019 & $0.42(0.32-0.54)$ & $<0.001$ \\
\hline Total & $40118(100)$ & $2518(6.3)$ & & & & \\
\hline
\end{tabular}

$p$ value in adjusted analysis obtained from the trend test(Wald) in logistic regression models.

*Adjusted for maternal factors (asthma,hypertension, parity and ART), parental smoking and neonatal factors (sex, gestational age at birth, mode of delivery and the onset of asthma or among controls the followup time). 
was most frequent in the highest SES group and nonplanned cesarean delivery in blue-collar workers. A total of $26.4 \%$ of blue-collar mothers had smoked, predisposing themselves to SGA infants and placental abruption (prevalences highest at $11.0 \%$ and $0.9 \%$ in this SES group) and to preeclampsia, which in turn predisposed them to non-elective cesarean delivery. Advanced maternal age, preterm birth and some delivery characteristics, such as placental abruption, preeclampsia and SGA infants are strongly associated with giving birth by cesarean section $[8,9,19]$.

We found no convincing evidence of a direct association between maternal SES and childhood asthma. Finnish public health services are available to all citizens and private services are also partly covered by the Social Insurance Institution. Furthermore, diagnosis and treatment of asthma is similar for all children. To be eligible to receive reimbursement payments under the Special Refund Categories the patient must obtain a certificate provided as a semi-structured form from a doctor and disease must be based on clinical diagnosis and criteria (ICD-10). In the case of pediatric asthma a certificate is usually issued by a pediatrician in order to confirm the nature of the disease and the need for long-term medication. Minor differences might be a result of the nature of access to care, or the quality of treatment of asthma in different SES groups [20]. Parental smoking during pregnancy was found to be a strong independent factor of asthma among the children of lower white-collar workers and among these smoking families children might also be likely to grow up in a smoking household. An interesting finding was that the prevalence of childhood asthma among blue-collar workers was lowest (6.0\%), even though smoking was most prevalent in that group. This may be related to reduced access to medical care in this group.

The most important strength of this study was that a large amount of data was collected from a single university hospital with uniform data-collection criteria and this therefore offered a comprehensive and reliable view of birth characteristics, perinatal outcome and socioeconomic factors. On the other hand, the register was produced mainly for administrative and statistical purposes rather than for research and therefore it might have included errors, and the percentage of missing SES values was $5.8 \%$, which is quite low number and possibly included younger women and immigrants taking care of their children at home and thus decreasing risk of asthma. National registers in Finland have been shown to be of high quality as regards validity and accuracy [21] and thus we obtained valuable and reliable information on pharmaceutical data. Information on SES was based solely on maternal occupation at the time of birth and information on household income and fathers' socioeconomic position was not available. However, in Finland income is known to correlate with occupation and therefore by proxy is sufficient to indicator for studies on socioeconomic health differences in perinatal period [22-24].

A limitation of our study was that ethnic/racial disparities in different countries are known to influence both SES and asthma [1,25]. In 2009 ethnic minorities constituted only $4 \%$ of the whole Finnish population [26], being a minority in our study population. We also lack information on parental smoking habits after birth and mothers' breastfeeding as additional confounding factors, also known to be risk factors of asthma. Furthermore, information on environmental risk factors such as day-care attendance, respiratory infections during childhood and pollution were not available, and mothers from lower-SES groups are known to be less likely to breastfeed their children and take them to day-care facilities $[1,3,27]$.

\section{Conclusion}

A direct association between SES and childhood asthma was not found in our Finnish population, but SES indirectly affects childhood asthma via adverse prenatal exposures $[14,17,28]$. Disparities are the result of the existence of differences in health behavior and healthcare use during pregnancy, especially as regards women from low social classes (i.e., unemployed or poorly educated). Such inequalities should be examined in public health and other public services at a wider level, to ensure equal opportunity of use.

\section{Abbreviations}

SES: Socioeconomic status; SGA: Small for gestational age; aOR: Adjusted odds ratio; $\mathrm{Cl}$ : Confidence interval.

\section{Competing interests}

The authors declare that they have no competing interests.

\section{Authors' contributions}

All authors (MH, LG, LK-N, KR, SR and SH) participated in designing the study. MH managed the dataset, performed statistical analyses and drafted the manuscript. LK-N gave advice regarding the statistical analyses. All authors contributed to interpretation of the results, as well as to the writing and editing of the manuscript. All authors read and approved the final manuscript.

\section{Acknowledgements}

The Pohjois-Savo Hospital District gave financial support (EVO- funding (awarded special state subsidy) for health science research).

The Corresponding Author has the right to grant on behalf of all authors and does grant on behalf of all authors, an exclusive copyright if and when the manuscript is accepted for publication, to permit this article to be published and the corresponding author will sign on behalf of co-authors a Copyright Transfer Agreement.

\section{Author details}

${ }^{1}$ Department of Obstetrics and Gynecology, Kuopio University Hospital, Kuopio, Finland. ${ }^{2}$ University of Eastern Finland, Faculty of Health Sciences, Kuopio, Finland. ${ }^{3}$ Helsinki University Central Hospital, Helsinki, Finland.

Received: 1 October 2014 Accepted: 5 January 2015

Published online: 28 January 2015 


\section{References}

1. Subbarao P, Mandhane PJ, Sears MR. Asthma: epidemiology, etiology and risk factors. CMAJ. 2009;181(9):E181-90.

2. Asher MI. Recent perspectives on global epidemiology of asthma in childhood. Allergol Immunopathol (Madr). 2010;38(2):83-7.

3. Algert CS, Bowen JR, Lain SL, Allen HD, Vivian-Taylor JM, Roberts CL. Pregnancy exposures and risk of childhood asthma admission in a population birth cohort. Pediatr Allergy Immunol. 2011;22(8):836-42.

4. Kozyrskyj AL, Bahreinian S, Azad MB. Early life exposures: impact on asthma and allergic disease. Curr Opin Allergy Clin Immunol. 2011;11(5):400-6.

5. Peters JL, Boynton-Jarrett R, Sandel M. Prenatal environmental factors influencing lgE levels, atopy and early asthma. Curr Opin Allergy Clin Immunol. 2013;13(2):187-92.

6. Tedner SG, Ortqvist AK, Almqvist C. Fetal growth and risk of childhood asthma and allergic disease. Clin Exp Allergy. 2012;42(10):1430-47.

7. Neu J, Rushing J. Cesarean versus vaginal delivery: long-term infant outcomes and the hygiene hypothesis. Clin Perinatol. 2011;38(2):321-31.

8. Raisanen S, Gissler M, Kramer MR, Heinonen S: Influence of delivery characteristics and socioeconomic status on giving birth by caesarean section - a cross sectional study during 2000-2010 in Finland. BMC Pregnancy Childbirth 2014, 14:120-2393-14-120.

9. Raisanen S, Gissler M, Sankilampi U, Saari J, Kramer MR, Heinonen S: Contribution of socioeconomic status to the risk of small for gestational age infants-a population-based study of 1,390,165 singleton live births in Finland. Int J Equity Health 2013, 12:28-9276-12-28.

10. Raatikainen K, Heiskanen N, Verkasalo PK, Heinonen S. Good outcome of teenage pregnancies in high-quality maternity care. Eur J Public Health. 2006;16(2):157-61.

11. Finnish Medicins Agency (FIMEA): ATC codes. [http://www.fimea.fi/ laaketieto/atc-luokitus]

12. Social Insurance Institution of Finland (Kela): Asthma Reimbursement. [http://www.kela.fi/laake203]

13. Statistics Finland: Information on the Social classification. [http://www.stat.fi/ meta/luokitukset/ammatti/001-2001/kuvaus_en.html]

14. Gissler M, Rahkonen O, Arntzen A, Cnattingius S, Andersen AM, Hemminki E. Trends in socioeconomic differences in Finnish perinatal health 1991-2006. J Epidemiol Community Health. 2009;63(6):420-5.

15. Hancox RJ, Milne BJ, Taylor DR, Greene JM, Cowan JO, Flannery EM, et al. Relationship between socioeconomic status and asthma: a longitudinal cohort study. Thorax. 2004;59(5):376-80.

16. Harju M, Keski-Nisula L, Georgiadis L, Raisanen S, Gissler M, Heinonen S. The burden of childhood asthma and late preterm and early term births. J Pediatr. 2014;164(2):295-9.e1.

17. Ekblad M, Gissler M, Korkeila J, Lehtonen L. Trends and risk groups for smoking during pregnancy in Finland and other Nordic countries. Eur J Public Health. 2014;24(4):544-51.

18. Midodzi WK, Rowe BH, Majaesic CM, Saunders LD, Senthilselvan A. Early life factors associated with incidence of physician-diagnosed asthma in preschool children: results from the Canadian Early Childhood Development cohort study. J Asthma. 2010;47(1):7-13.

19. Raisanen S, Gissler M, Saari J, Kramer M, Heinonen S. Contribution of risk factors to extremely, very and moderately preterm births - register-based analysis of 1,390,742 singleton births. PLoS One. 2013;8(4):e60660.

20. Mielck A, Reitmeir P, Wjst M. Severity of childhood asthma by socioeconomic status. Int J Epidemiol. 1996;25(2):388-93.

21. Gissler M, Teperi J, Hemminki E, Merilainen J. Data quality after restructuring a national medical registry. Scand J Soc Med. 1995;23(1):75-80.

22. Gissler M, Merilainen J, Vuori E, Hemminki E. Register based monitoring shows decreasing socioeconomic differences in Finnish perinatal health. J Epidemiol Community Health. 2003;57(6):433-9.

23. Mortensen LH, Lauridsen JT, Diderichsen F, Kaplan GA, Gissler M, Andersen AM. Income-related and educational inequality in small-for-gestational age and preterm birth in Denmark and Finland 1987-2003. Scand J Public Health. 2010;38(1):40-5.

24. Raisanen S, Randell K, Nielsen HS, Gissler M, Kramer MR, Klemetti R, et al. Socioeconomic status affects the prevalence, but not the perinatal outcomes, of in vitro fertilization pregnancies. Hum Reprod. 2013;28(11):3118-25.

25. Blumenshine P, Egerter S, Barclay CJ, Cubbin C, Braveman PA. Socioeconomic disparities in adverse birth outcomes: a systematic review. Am J Prev Med. 2010;39(3):263-72.
26. Malin M, Gissler M: Maternal care and birth outcomes among ethnic minority women in Finland. BMC Public Health 2009, 9:84-2458-9-84.

27. Ruijsbroek A, Wijga AH, Kerkhof M, Koppelman GH, Smit HA, Droomers M: The development of socio-economic health differences in childhood: results of the Dutch longitudinal PIAMA birth cohort. BMC Public Health 2011, 11:225-2458-11-225.

28. Raisanen S, Gissler M, Nielsen HS, Kramer MR, Williams MA, Heinonen S. Social disparity affects the incidence of placental abruption among multiparous but not nulliparous women: a register-based analysis of 1,162,126 singleton births. Eur J Obstet Gynecol Reprod Biol. 2013;171(2):246-51.

\section{Submit your next manuscript to BioMed Central and take full advantage of:}

- Convenient online submission

- Thorough peer review

- No space constraints or color figure charges

- Immediate publication on acceptance

- Inclusion in PubMed, CAS, Scopus and Google Scholar

- Research which is freely available for redistribution 